\title{
A systematic review of concepts related to women's empowerment in the perinatal period and their associations with perinatal depressive symptoms and premature birth
}

Esmeralda R. Garcia and Ilona S. Yim*

\begin{abstract}
Background: The perinatal period, which we here define as pregnancy and the first year postpartum, is a time in women's lives that involves significant physiological and psychosocial change and adjustment, including changes in their social status and decision-making power. Supporting women's empowerment at this particular time in their lives may be an attractive opportunity to create benefits for maternal and infant health outcomes such as reductions in perinatal depressive symptoms and premature birth rates. Thus, we here systematically review and critically discuss the literature that investigates the effects of empowerment, empowerment-related concepts and empowerment interventions on reductions in perinatal depressive symptoms, preterm birth (PTB), and low birthweight (LBW).
\end{abstract}

Methods: For this systematic review, we conducted a literature search in Psychlnfo, PubMed, and CINAHL without setting limits for date of publication, language, study design, or maternal age. The search resulted in 27 articles reporting on 25 independent studies including a total of 17,795 women.

Results: The majority of studies found that, for the most part, measures of empowerment and interventions supporting empowerment are associated with reduced perinatal depressive symptoms and PTB/LBW rates. However, findings are equivocal and a small portion of studies found no significant association between empowerment-related concepts and perinatal depressive symptoms and PTB or LBW.

Conclusion: This small body of work suggests, for the most part, that empowerment-related concepts may be protective for perinatal depressive symptoms and PTB/LBW. We recommend that future theory-driven and integrative work should include an assessment of different facets of empowerment, obtain direct measures of empowerment, and address the relevance of important confounders, including for example, ethnicity and socioeconomic status.

Keywords: Empowerment, Perinatal depression, Preterm birth, Low birthweight, Prematurity

\footnotetext{
* Correspondence: ilona.yim@uci.edu

Department of Psychology and Social Behavior, University of California, 4562

Social and Behavioral Sciences Gateway, Irvine, CA 92697-7085, USA
} 


\section{Background}

Women's empowerment can lead to significant positive changes in many domains. In terms of health, studies have found an association between increased empowerment and reduced mortality and morbidity [1, 2]. For example, empowerment interventions have been associated with decreases in blood glucose and cholesterol levels among women with pre-diabetes and high cardiovascular disease risk [3]. In terms of reproductive health, empowerment has been associated with reduced rates of unintended pregnancies [4] and sexually transmitted diseases, such as chlamydia and gonorrhea, in high-risk populations [5]. Other studies have shown benefits of empowerment for health-related behaviors such as obtaining nutritional supplements and participating in health education sessions [6].

The benefits of empowerment are not necessarily limited to women themselves, but have the potential to extend to those around her, including - perhaps most prominently her own children. Stressors experienced during pregnancy not only result in physiological alterations in the pregnant woman, but these biological signals can be communicated to the unborn child via placental transmission, and have been associated with outcomes including preterm birth (PTB) and postpartum depression [7, 8].

The perinatal period, here defined as pregnancy and the first year postpartum, is also a time in women's lives that involves significant physiological and psychosocial change and adjustment, including changes in women's social status and decision-making power. Supporting women's empowerment at this particular time may be an opportunity to create long-lasting benefits, not only for the new mother, but also for her newborn. One of the earliest measures of infant health are measures of prematurity including PTB and low birthweight (LBW), and there is convincing evidence that being born prematurely poses a risk factor for poorer health outcomes throughout the life span (e.g., [9]). In terms of maternal health, an early birth outcome is the presence and degree of postpartum depressive symptoms, which in the broader postpartum depression literature have been assessed to occur anywhere between 1 day and 1 year postpartum [10]. It has been argued that the biobehavioral pathways leading to PTB and postpartum depression and its symptoms may overlap [11], which led us to include both health outcomes in this review.

Herein, we systematically review the literature testing the link between perinatal maternal empowerment and perinatal depressive symptoms as well as PTB and LBW. Because the number of studies testing these associations is very small, we chose to define empowerment in its broadest sense as a person's autonomy, decision-making power, and self-determination. We also decided to include studies on empowerment-related concepts that merely relate to or impact on empowerment if the authors' discussion of the methods used fell within the framework of empowerment. Conceptualizations of empowerment and its related concepts among studies in this review include, for example, relationship power, equity, self-efficacy reflected in women's financial independence, reductions in intimate partner violence, and increases in domestic decision-making power.

The present review includes observational studies assessing the degree of empowerment and empowermentrelated concepts through questionnaires, as well as studies supporting women's empowerment by implementing programs intended to increase women's empowerment, which we here refer to as empowerment interventions. Of note, among the intervention studies, only one actually measured changes in an empowerment-related concept [12]. Moreover, the interventions in the studies reported here were not always designed to improve a health outcome by changes in empowerment alone. Table 1 shows which measure or intervention was used for each study, and how empowerment was conceptualized.

\section{Methods}

\section{Search strategy}

We conducted a literature search in PsychINFO, PubMed, and CINAHL, according to guidelines in the PRISMA (Preferred Reporting Items for Systematic Reviews and Meta-Analyses) statement [13]. The terms 'agency', 'autonomy', 'choice,' 'control,' 'domestic decisionmaking power,' 'economy', 'empower,' 'empowerment,' 'fertility intervention', 'leadership', 'power,' 'pregnancy', 'resources', 'transformation', 'voice,' and 'women's health' were combined with the search terms 'birth,' 'birthweight', 'preterm,' 'depression in pregnancy', 'perinatal depression', 'postpartum depression', and 'premature birth'. The search terms 'CenteringPregnancy', 'child marriage', and 'sexual activity' also emerged as relevant due to their presence in the initial search results, and the three terms were thus added to the final search.

\section{Inclusion and exclusion criteria}

To be included in this review, studies had to be peerreviewed and include (1) a sample of women who were either pregnant or within the first year postpartum; (2) a measure of empowerment or lack thereof or an intervention aimed at supporting women's empowerment; and (3) a measure of perinatal depressive symptoms or of prematurity (PTB, LBW). Of note, whereas PTB/LBW is determined at the time of birth, maternal depressive symptoms can occur in the postpartum period as well. Thus, studies of empowerment in the first year postpartum were only relevant to the literature on depressive symptoms. We identified 1 study assessing depressive symptoms during pregnancy, 11 in the postpartum 
Table 1 Table of concepts

\begin{tabular}{|c|c|c|c|}
\hline Measure of empowerment or intervention & Empowerment components & & References \\
\hline & Intervention & Direct measure & \\
\hline \multicolumn{4}{|l|}{ INTERVENTION STUDIES } \\
\hline CenteringPregnancy (CP) & $\begin{array}{l}\text { Self-efficacy, self-care, self-esteem, } \\
\text { knowledge }\end{array}$ & & {$[15,17,24,25,29,33-41]$} \\
\hline $\begin{array}{l}\text { Parent-to-parent and } \\
\text { parent-to-provider dialogue }\end{array}$ & $\begin{array}{l}\text { Self-efficacy, partnership, participation, } \\
\text { collaboration, awareness, sense of } \\
\text { control, self-help, meeting personal } \\
\text { needs, access to resources, } \\
\text { and personal action }\end{array}$ & & [18] \\
\hline Guided Participation & Self-confidence, self-efficacy & & [22] \\
\hline Health locus of control & $\begin{array}{l}\text { Internal health locus of control, } \\
\text { self-efficacy, health knowledge }\end{array}$ & Health locus of control & [12] \\
\hline Mom Power & $\begin{array}{l}\text { Self-confidence, parenting } \\
\text { competence, self-efficacy, } \\
\text { knowledge, self-care }\end{array}$ & & [23] \\
\hline $\begin{array}{l}\text { Creating Opportunity for } \\
\text { Parent Empowerment (COPE) }\end{array}$ & $\begin{array}{l}\text { Parenting confidence and } \\
\text { knowledge, participation in } \\
\text { care, self-confidence, control }\end{array}$ & & {$[26-28]$} \\
\hline \multicolumn{4}{|l|}{ OBSERVATIONAL STUDIES } \\
\hline $\begin{array}{l}\text { Gender hierarchies within the } \\
\text { family, unequal power relationships, } \\
\text { domestic decision-making power }\end{array}$ & & Agency, decision-making power & [14] \\
\hline Locus of control & & $\begin{array}{l}\text { Internal locus of control, self- efficacy, } \\
\text { self-competence }\end{array}$ & [16] \\
\hline $\begin{array}{l}\text { Intimate partner violence, } \\
\text { relationship power, and equity }\end{array}$ & & Relationship power & [20] \\
\hline $\begin{array}{l}\text { Domestic violence and not } \\
\text { having the right to plan pregnancy }\end{array}$ & & Agency, decision-making power & [30] \\
\hline $\begin{array}{l}\text { Debt and lack of financial } \\
\text { decision-making power }\end{array}$ & & Agency, decision-making power & {$[31]$} \\
\hline Domestic decision-making power & & Agency, decision-making power & [32] \\
\hline
\end{tabular}

period, and 4 in both pregnancy and postpartum. Empowerment was measured or an intervention supporting empowerment was administered postpartum for 9 studies, in pregnancy for 3 studies, and in both for 4 studies. No limits were set for date of publication, maternal age, study design, or language of publication; nevertheless, only English language publications were identified.

\section{Selected studies}

The literature search identified 150 records in PubMed, 74 records in PsycINFO and 40 records in CINAHL (see Fig. 1 for PRISMA flow chart). After removing 30 duplicates, 234 articles were screened for eligibility. Five records were excluded based on title and abstract reviews because they were animal studies. Of the remaining 229 full-text articles, 202 records were excluded because they did not include a measure of empowerment or an intervention supporting empowerment $(n=74)$; did not measure perinatal depressive symptoms, PTB, or LBW $(\mathrm{n}=72)$; or lacked a measure of empowerment as well as perinatal depressive symptoms and PTB or LBW $(n=56)$. The remaining 27 articles were included in this manuscript. These articles report on 25 independent studies with a total of 17,795 participants. Across studies, sample sizes ranged from 30 [14] to 6155 [15], with a mean of 693 participants $(S D=1196)$. Most studies were conducted in the US (70.83\%), and the remaining studies in Iran, Pakistan (both $8.33 \%$ ), Taiwan, Canada, and the Netherlands (all $4.17 \%$ ). Of the studies conducted in the US, one did not provide ethnicity information [16]. In the remaining studies, the majority of participants were African-American (36.27\%), followed by White (28.13\%), Hispanic (24.42\%), Asian (7.01\%), Native American $(<1 \%)$, and Other $(4 \%)$. Average participant ages ranged from 15 [17] to 33 years old [18]. Across studies, participants were an average of 25.01 years old $(\mathrm{SD}=3.79)$.

\section{Quality ratings}

Study quality ratings were conducted according to $\mathrm{Na}$ tional Institute of Health standards for controlled 


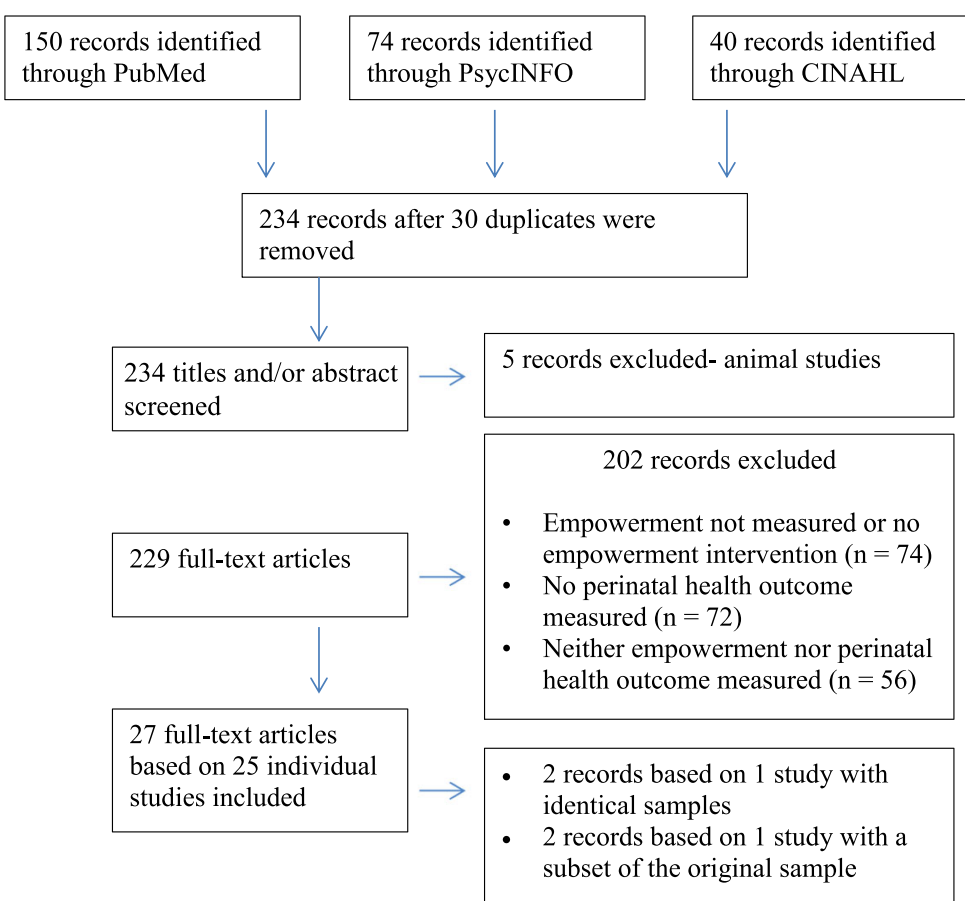

Fig. 1 Flowchart following guidelines in the PRISMA (Preferred Reporting Items for Systematic Reviews and Meta-Analyses) statement [13]

intervention studies as well as for observational, cohort, and cross-sectional studies [19]. We considered studies with a quality score of eight to 14 of good quality, and those with scores of five to seven as fair. While the National Institute of Health standards recommend to not base quality ratings on sum scores alone, we contend that this categorization also matched our individual readings of each study. No studies were considered to be of poor quality.

\section{Conceptualizations of empowerment}

We identified six studies that assessed empowerment in cross-sectional/observational study designs and 19 studies that reported on empowerment interventions. Observational studies used mostly self-report or interview measures, such as the Decision-Making Dominance Subscale of the Sexual Relationship Power Scale [20] and critical ethnographic interviews [14]. Studies used different types of empowerment interventions (see Table 1 for details). The majority report on CenteringPregnancy (CP), a group prenatal care model. "CenteringPregnancy unifies the components of prenatal care-risk assessment, education, and support within the group-and encourages women to take responsibility for their own health" ([21], p. 46). CP was included in this review because it aims to empower women by increasing their health selfcare efficacy during pregnancy. "The woman's involvement in self-care activities, the discussion and education format, the worksheets and handouts, and the sharing among the women all lead to her enhanced sense of empowerment. This, in turn, results in a sharing of power between the provider and the consumer" ([21], p. 53). Other studies report on the Creating Opportunities for Parent Empowerment (COPE) program for parents with premature infants in Neonatal Intensive Care Units. COPE aims to inform parental decision-making and increase parental knowledge about infant developmental outcomes, consequently easing parent-infant interactions. Thus, it aims to support women's empowerment by increas[es]ing parenting confidence, participation in care, self-confidence, and control, affecting health outcomes including reducing parenting anxiety and depressive symptoms as well as reducing their stay in the Neonatal Intensive Care Units.

The remaining studies used various other interventions. The first is the Guided Participation program. It is included in the framework of empowerment-related models because it acts on autonomy and selfdetermination by informing mothers of premature infants of effective premature infant care and increases parenting self-efficacy, feeding competencies, and positive infant behaviors to reduce anxiety and depressive symptoms associated with parenting a premature infant [22]. This has empowerment implications in terms of promoting self-confidence among mothers of premature infants who may feel helpless, scared, and might lack confidence in their ability to care for their premature newborn. The second is an internal health locus of control intervention that aims to promote empowerment of 
women through education about self-care such as pregnancy stage monitoring, nutrition, and health [12]. One study reports on a parent-to-parent and parent-toprovider dialogue intervention related to participation, collaboration, awareness, sense of control, self-efficacy, and self-help as well as access to resources and personal action to shift the personal health decision-making power from healthcare provider to client [18]. Finally, Mom Power is a parenting and self-care skills group program for high-risk mothers and their young children that aims to empower by increasing parenting and selfcare knowledge [23].

\section{Results}

Of the 27 manuscripts included in this review, 16 report on maternal perinatal depressive symptoms and 11 studies report on PTB or LBW. No studies that addressed both maternal and infant outcomes were identified, and we therefore report on the two types of outcomes separately.

\section{Maternal perinatal depressive symptoms}

Of the 16 studies reporting on perinatal depressive symptoms, 10 were intervention studies and 6 were observational studies (Table 2); 15 studies assessed depressive symptoms postpartum and 12 yielded significant findings (80\%), whereas only 2 out of 5 studies (40\%) yielded significance when depressive symptoms were assessed in pregnancy. Nine out of 11 studies rated as good (82\%) and 4 out of 5 studies rated as fair $(80 \%)$ yielded significance.

\section{Intervention studies}

Among the intervention studies were seven randomized controlled trials [12, 22, 24-28], two quasi-experimental studies [18, 29], and one prospective cohort study [23].

Three of the randomized controlled trials, all by the same team of authors, used the COPE program as an experimental intervention. The first of this set of studies evaluated COPE in a small sample of 42 mothers of premature infants [26]. When depressive symptoms were assessed 4 to 8 days after admission and 1 to 4 days prior to discharge, women receiving the intervention had fewer depressive symptoms than those receiving traditional care. However, no differences were observed when scores were aggregated across all phases of the intervention. A second study of 260 families confirms that mothers in COPE report fewer post-hospital depressive symptoms than those in the control group, and further expands by suggesting that COPE may also reduce parental stress [27]. The last article reporting on a subset of 246 mothers found participation in COPE was related not only to mothers' decreased post-hospital depressive symptoms, but also to reduced anxiety [28]. Thus, while
COPE was conceptualized to improve premature infant health and developmental outcomes, the findings of these three studies suggest that COPE may also be an effective tool for reducing maternal postpartum symptoms of depression, stress, and anxiety.

Two studies reported on $\mathrm{CP}$ randomized controlled trials $[24,25]$. Among women who initially reported high stress, those in a ' $\mathrm{CP}+$ ' group, which added information about HIV prevention as well as components of psychosocial functioning such as behavioral risk assessment, goal setting, communication, and negotiation skills, had significantly fewer depressive symptoms at 1 year postpartum than those in the standard $\mathrm{CP}$ and control groups [24]. These findings may suggest that CP could be useful in terms of improving maternal depressive symptoms if it also addresses the specific needs of the patient population. Another CP study of 322 pregnant women in the military found no differences in prenatal or postnatal depressive symptoms between those in a CP condition and those receiving standard care [25]. Similarly, a smaller quasi-experimental study of 49 Hispanic women suggests no significant differences in perinatal depressive symptoms between those in $\mathrm{CP}$ and those receiving traditional care [29]. However, in addition to the small sample, the study groups differed in that those in the $\mathrm{CP}$ group had more primigravidas.

Of the remaining studies, three found significant associations between empowerment and perinatal depressive symptoms. The strongest support comes from a prospective cohort study of 80 mother-child pairs who participated in the Mom Power intervention. Results suggest that participation in Mom Power is not only associated with significant reduction in depressive symptoms, but also with lower symptoms indicative of post-traumatic stress disorder risk and reduced caregiving helplessness [23]. Another study empowered women by providing an internal health locus of control intervention and found significant increases in internal health locus of control as well as lower postpartum depressive symptoms among those in the intervention group [12]. Similarly, a study of 70 Taiwanese parents of preterm infants, using a parent-to-parent and parent-to-provider dialogue, found that postintervention depression scores were significantly lower for those in the intervention than for those in the control group. Those in the intervention group also had higher childrearing self-efficacy [18]. In contrast, findings from a small study of 42 mothers with very LBW infants $(\leq 1200 \mathrm{~g})$ indicate no differences in maternal perinatal depressive symptoms between those in the Guided Participation and control groups [22]. However, those in the intervention group were better able to regulate infant negative 


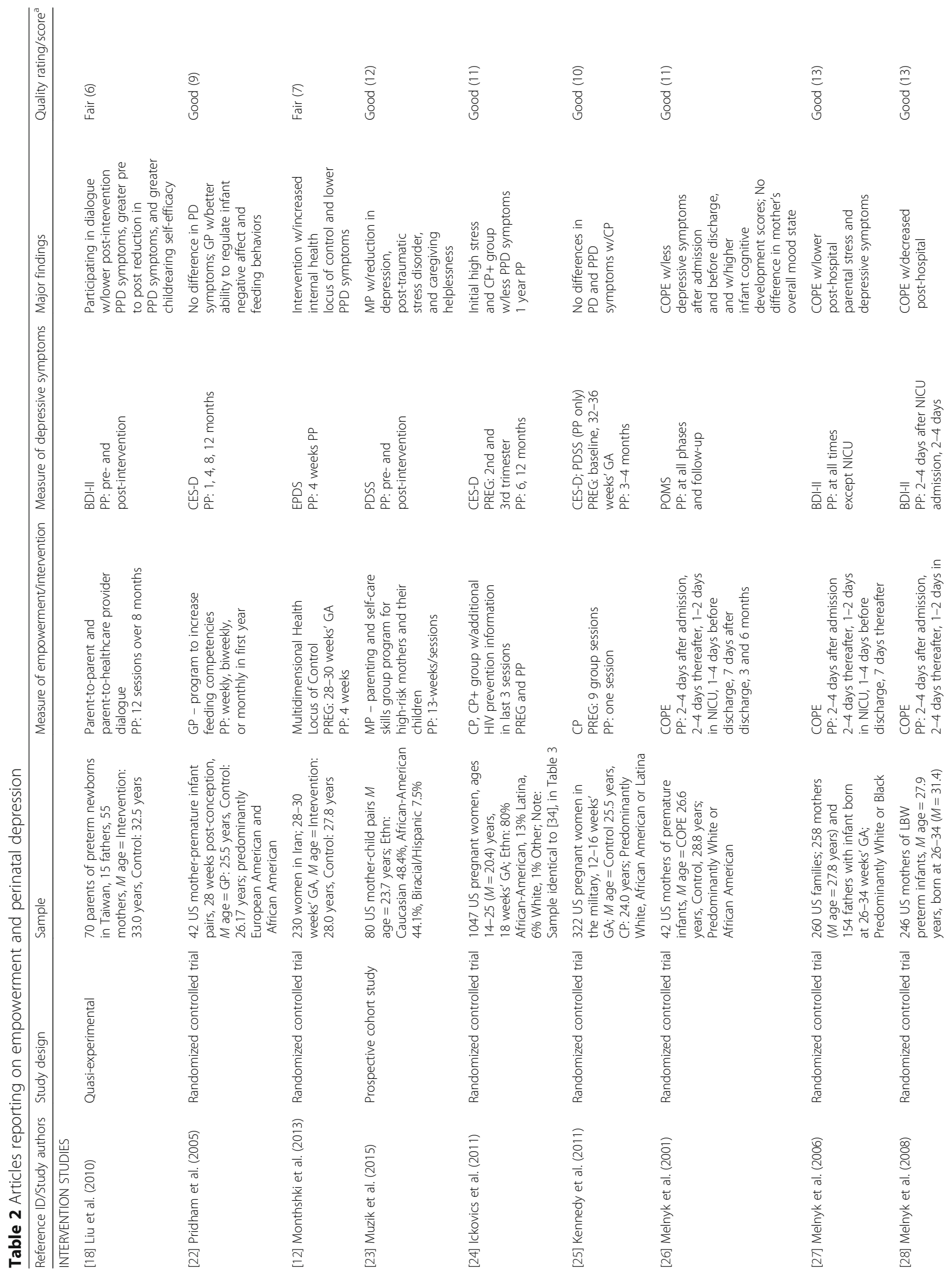




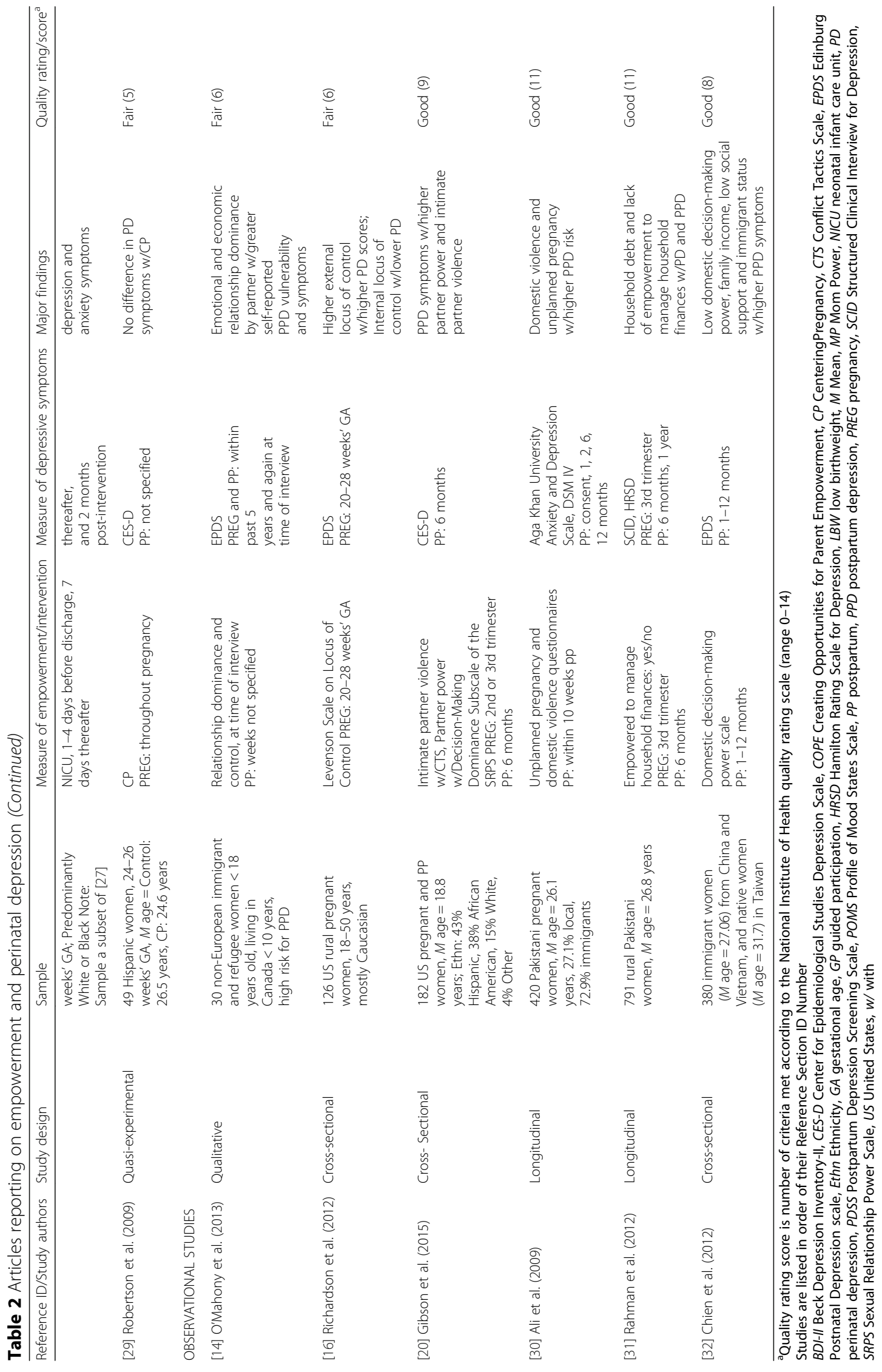


affect and feeding behaviors than those in the control group.

\section{Observational studies}

Among the 6 observational studies, 2 were longitudinal [30, 31], 3 cross-sectional [16, 20,32], and 1 used a qualitative study design [14]. Despite variations in definitions of empowerment, all quantitative studies yielded significance, and studies suggest a positive association between perinatal depressive symptoms and domestic violence [20,30], emotional and economic relationship dominance by an intimate partner [14], and external locus of control [16] as well as negative associations with domestic decision-making power [32] and the power to manage household finances [31].

\section{Summary}

In sum, all observational and all but three of the intervention studies $[22,25,29]$ suggest reduced perinatal depressive symptoms with empowerment. More specifically, studies using the COPE, Mom Power, internal health locus of control, parent-to-parent and parent-to-provider dialogue interventions were effective in reducing maternal perinatal depressive symptoms. In contrast, the CP intervention did not significantly improve maternal affect, unless adaptations specific to the study population were made. Similarly, the Guided Participation intervention did not improve maternal health outcomes, likely because it was not primarily developed to address maternal health outcomes, but to improve infant feeding competencies and affect regulation.

\section{PTB and LBW}

All 11 studies on PTB and LBW were intervention studies and all used the CP intervention (Table 3). Of these, one was a prospective cohort study [33], two were randomized controlled trials [34, 35], and eight were retrospective cohort studies $[15,17,36-41]$. The prospective cohort study [33] reports that mothers in CP had infants with higher birth weight and longer gestational age at birth than those in the control group. Moreover, among those who delivered preterm, the CP group participants maintained gestation for significantly longer. Similarly, a randomized controlled trial of 1148 women found reduced rates of PTB and LBW among women in the $\mathrm{CP}+$ group [35]. A second randomized controlled trial of 1047 women reports that those in the $\mathrm{CP}$ group were significantly less likely to have PTB in comparison to the control group, but no significant group differences were found for LBW [34]. This study also reports a dose-response effect such that gestational age decreased in relation to the number of group sessions missed, suggesting the null findings may be attributable to factors other than lack of effectiveness of the intervention. All of the studies were rated as good quality, ranging from 9 to 12 , but studies that found no significance tended to be those at the lower end of the good quality range, receiving scores of 9 and 10.

Among the eight retrospective cohort studies, five provided evidence of at least some associations between empowerment and prematurity. One of these studies found $\mathrm{CP}$ to be associated with lower PTB and LBW rates in a sample of 124 adolescents [17]. Three studies, including samples of 216 Latinas [39] as well as ethnically diverse samples of 4083 [38] and 379 [36] women, had mixed findings, reporting reductions in the rate of PTB but not of LBW. A final study reports higher birth weight and higher gestational age at birth as well as significantly reduced risk of very LBW in the CP compared to the control group [15].

The remaining three retrospective cohort studies, all with homogenous samples including 268 AfricanAmerican women [37], 487 Latinas [40], and 404 US military women [41], suggest no impact of $\mathrm{CP}$ on either PTB or LBW. These null findings may, at least in part, be explained by confounding variables. For example, one study reports that those in $\mathrm{CP}$ were significantly younger than those in standard care [37], and another reports that those in $\mathrm{CP}$ were more likely to be in active duty, younger, and primiparous [41], but these variables were not statistically controlled for.

\section{Summary}

Six of the CP studies found significant benefits for PTB and/or LBW, with an additional two studies suggesting benefits for gestational age and birthweight. Specifically, a retrospective cohort study and a randomized controlled trial utilizing the $\mathrm{CP}+$ intervention found significant benefits of CP for both PTB and LBW. An additional four studies found an association between $\mathrm{CP}$ and reduced PTB, but not LBW. Similarly, two studies found significantly higher gestational age at birth and birthweight among $\mathrm{CP}$ participants compared to those in the control group; however, effects for PTB and LBW did not reach significance. Three other $\mathrm{CP}$ studies found no significant association with gestational age, birthweight, PTB, or LBW. Confounds related to sample characteristics and study design may play an important role in the effectiveness of $\mathrm{CP}$.

\section{Discussion}

We set out to systematically review the relatively small literature on empowerment and maternal and infant health. While all studies meeting inclusion criteria conceptualized their measures in the context of empowerment, none of the studies included a measure of empowerment. Instead, facets of empowerment or concepts related to empowerment were assessed in all 
Table 3 Articles reporting on empowerment and preterm birth/low birthweight

\begin{tabular}{|c|c|c|c|c|c|c|}
\hline $\begin{array}{l}\text { Reference } \\
\text { ID/Study } \\
\text { authors }\end{array}$ & $\begin{array}{l}\text { Study design } \\
\text { (all are } \\
\text { interventions) }\end{array}$ & Sample & $\begin{array}{l}\text { Measure of } \\
\text { empowerment/ } \\
\text { intervention }\end{array}$ & $\begin{array}{l}\text { Measure } \\
\text { of PTB/ } \\
\text { LBW }\end{array}$ & Major findings & $\begin{array}{l}\text { Quality } \\
\text { rating/ } \\
\text { score }^{a}\end{array}$ \\
\hline $\begin{array}{l}15] \\
\text { Tanner- } \\
\text { Smith et al. } \\
(2014)\end{array}$ & $\begin{array}{l}\text { Retrospective } \\
\text { cohort study }\end{array}$ & $\begin{array}{l}6155 \text { US pregnant women, } M \text { age }= \\
25.0 \text { years; African American } 49.9 \% \text {, White } \\
30.3 \% \text {, Hispanic } 20.7 \%\end{array}$ & $\begin{array}{l}\mathrm{CP} \text {, throughout } \\
\text { pregnancy }\end{array}$ & MR & $\begin{array}{l}\text { CP w/longer gestation, } \\
\text { higher birth weight, lower } \\
\text { odds of very LBW, but not } \\
\text { LBW or PTB }\end{array}$ & $\begin{array}{l}\text { Good } \\
(12)\end{array}$ \\
\hline $\begin{array}{l}\text { [17] Grady } \\
\text { et al. (2004) }\end{array}$ & $\begin{array}{l}\text { Retrospective } \\
\text { cohort study }\end{array}$ & $\begin{array}{l}124 \text { US pregnant adolescents, } M \text { age }=\text { CP: } \\
15.8 \text { years, } 2001 \text { comparison: } 16.5 \text { years, } 1998 \\
\text { comparison: } 16.3 \text { years; } 12-18 \text { weeks' GA; } \\
\text { Predominantly African American }\end{array}$ & $\begin{array}{l}\mathrm{CP}, 12-18 \text { weeks' GA, } \\
\text { and every } 2 \text { weeks } \\
\text { until } 8 \text { weeks } \\
\text { postpartum }\end{array}$ & $\mathrm{MR}$ & $\begin{array}{l}\text { CP group w/less LBW and } \\
\text { PTB }\end{array}$ & $\begin{array}{l}\text { Good } \\
(11)\end{array}$ \\
\hline $\begin{array}{l}{[33]} \\
\text { Ickovics et } \\
\text { al. (2003) }\end{array}$ & $\begin{array}{l}\text { Prospective } \\
\text { cohort study }\end{array}$ & $\begin{array}{l}458 \text { US pregnant women, } 12-40 \text { years }(M= \\
21.6) ; \leq 24 \text { weeks' GA; African American } 80 \% \text {, } \\
\text { Latina } 15 \% \text {, and White } 5 \%\end{array}$ & $\begin{array}{l}\mathrm{CP} \text {, throughout } \\
\text { pregnancy }\end{array}$ & $\mathrm{MR}$ & $\begin{array}{l}\text { CP w/higher birth weight } \\
\text { and longer gestation, but } \\
\text { not PTB or LBW }\end{array}$ & $\begin{array}{l}\text { Good } \\
(11)\end{array}$ \\
\hline $\begin{array}{l}{[34]} \\
\text { Ickovics et } \\
\text { al. (2007) }\end{array}$ & $\begin{array}{l}\text { Randomized } \\
\text { controlled } \\
\text { trial }\end{array}$ & $\begin{array}{l}1047 \text { US pregnant women, } 14-25 \text { years }(M= \\
\text { 20.4); } 18 \text { weeks' GA; Predominantly African } \\
\text { American and Latina }\end{array}$ & $\begin{array}{l}\mathrm{CP} \text {, throughout } \\
\text { pregnancy }\end{array}$ & $\mathrm{MR}$ & $\begin{array}{l}\text { CP group w/lower } \\
\text { likelihood of PTB, but not } \\
\text { LBW }\end{array}$ & $\begin{array}{l}\text { Good } \\
(11)\end{array}$ \\
\hline $\begin{array}{l}{[35]} \\
\text { Ickovics et } \\
\text { al. (2016) }\end{array}$ & $\begin{array}{l}\text { Randomized } \\
\text { controlled } \\
\text { trial }\end{array}$ & $\begin{array}{l}1148 \text { US pregnant women, } 14-21 \text { years; < } \\
24 \text { weeks' GA; Predominantly Latina, Black, } \\
\text { White }\end{array}$ & $\begin{array}{l}\mathrm{CP}+\text {, throughout } \\
\text { pregnancy }\end{array}$ & $\mathrm{MR}$ & $\begin{array}{l}\text { Greater number of CP visits } \\
\text { W/lower odds of small for } \\
\text { GA neonate, PTB, and LBW }\end{array}$ & $\begin{array}{l}\text { Good } \\
(11)\end{array}$ \\
\hline $\begin{array}{l}\text { [36] Barr et } \\
\text { al. (2011) }\end{array}$ & $\begin{array}{l}\text { Retrospective } \\
\text { cohort study }\end{array}$ & $\begin{array}{l}379 \text { US pregnant women, } M \text { age CP: } \\
27.1 \text { years, Control: } 27.4 \text { years; Predominantly } \\
\text { Hispanic, Black, White }\end{array}$ & $\begin{array}{l}C P \text {, in pregnancy; GA } \\
\text { not specified }\end{array}$ & $\mathrm{MR}$ & $\begin{array}{l}\text { CP w/lower odds of PTB } \\
\text { and a trend toward less } \\
\text { LBW compared to standard } \\
\text { care }\end{array}$ & $\begin{array}{l}\text { Good } \\
(9)\end{array}$ \\
\hline $\begin{array}{l}\text { [37] Klima } \\
\text { et al. (2009) }\end{array}$ & $\begin{array}{l}\text { Retrospective } \\
\text { cohort study }\end{array}$ & $\begin{array}{l}268 \text { US pregnant women, ages 14-38 (21.8) } \\
\text { years, } \leq 18 \text { weeks' GA; } 100 \% \text { African American }\end{array}$ & $\begin{array}{l}\mathrm{CP} \text {, throughout } \\
\text { pregnancy }\end{array}$ & MR & $\begin{array}{l}\text { No difference in PTB and } \\
\text { LBW w/CP }\end{array}$ & $\begin{array}{l}\text { Good } \\
(10)\end{array}$ \\
\hline $\begin{array}{l}{[38]} \\
\text { Picklesimer } \\
\text { et al. (2012) }\end{array}$ & $\begin{array}{l}\text { Retrospective } \\
\text { cohort study }\end{array}$ & $\begin{array}{l}4083 \text { US pregnant women, } M \text { age }= \\
23.1 \text { years, } \leq 16 \text { weeks' GA; Predominantly } \\
\text { White, Black or Hispanic }\end{array}$ & $\begin{array}{l}\mathrm{CP} \text {, throughout } \\
\text { pregnancy }\end{array}$ & $\mathrm{MR}$ & CP w/less PTB, but not LBW & $\begin{array}{l}\text { Good } \\
(11)\end{array}$ \\
\hline $\begin{array}{l}{[39]} \\
\text { Tandon et } \\
\text { al. (2012) }\end{array}$ & $\begin{array}{l}\text { Retrospective } \\
\text { cohort study }\end{array}$ & $\begin{array}{l}216 \text { US pregnant women, } M \text { age }=C P \text { : } \\
27.4 \text { years, Control: } 27.5 \text { years; } \leq 20 \text { weeks' GA; } \\
100 \% \text { Hispanic/Mayan }\end{array}$ & $\begin{array}{l}\mathrm{CP} \text {, throughout } \\
\text { pregnancy }\end{array}$ & $\mathrm{MR}$ & $\begin{array}{l}\text { CP w/lower PTB, but not } \\
\text { LBW }\end{array}$ & $\begin{array}{l}\text { Good } \\
(10)\end{array}$ \\
\hline $\begin{array}{l}\text { [40] } \\
\text { Trudnack } \\
\text { et al. (2013) }\end{array}$ & $\begin{array}{l}\text { Retrospective } \\
\text { cohort study }\end{array}$ & $\begin{array}{l}487 \text { US pregnant women, } \mathrm{M} \text { age }=25.6 \text { years; } \\
100 \% \text { Latinas }\end{array}$ & $\begin{array}{l}\mathrm{CP} \text {, throughout } \\
\text { pregnancy }\end{array}$ & $\mathrm{MR}$ & $\begin{array}{l}\text { No difference in LBW or PTB } \\
W / C P\end{array}$ & $\begin{array}{l}\text { Good } \\
(9)\end{array}$ \\
\hline $\begin{array}{l}\text { [41] Walton } \\
\text { et al. (2015) }\end{array}$ & $\begin{array}{l}\text { Retrospective } \\
\text { cohort study }\end{array}$ & $\begin{array}{l}404 \text { US pregnant women in the military, M } \\
\text { age = CP: } 24.8 \text { years, Control: } 26.3 \text { years; } \\
\text { Predominantly Caucasian, Asian, African } \\
\text { American }\end{array}$ & $\begin{array}{l}\mathrm{CP} \text {, throughout } \\
\text { pregnancy }\end{array}$ & $\mathrm{MR}$ & $\begin{array}{l}\text { No significant difference in } \\
\text { LBW and PTB w/CP }\end{array}$ & $\begin{array}{l}\text { Good } \\
(9)\end{array}$ \\
\hline
\end{tabular}

${ }^{a}$ Quality rating score is number of criteria met according to the National Institute of Health quality rating scale (range 0-14) Studies are listed in order of their Reference Section ID Number

$C P$ CenteringPregnancy, GA gestational age, LBW low birthweight, $M$ [median]mean, MR medical records, PTB preterm birth, US United States, $w /$ with

cross-sectional studies and in one intervention study. The remaining intervention studies did not assess empowerment, limiting the conclusions that can be drawn about the role of maternal empowerment interventions in maternal and infant health. However, it is remarkable that despite the differences in how maternal empowerment was conceptualized across studies, the majority of studies provide fairly consistent evidence for a link between what was conceptualized as maternal perinatal empowerment and reduced perinatal depressive symptoms and PTB/LBW rates.

In determining why, among the intervention studies, some yielded significance whereas others did not, the conceptualization of empowerment appears to play an important role. All studies of empowerment and prematurity, and the majority of studies on maternal perinatal depressive symptoms used $\mathrm{CP}$ as an empowerment strategy. Our review suggests that, in the majority of studies, CP was successful at improving infant outcomes. In contrast, CP was not associated with lower maternal perinatal depressive symptoms, unless the intervention was modified to include components specific to the study population (i.e., the $\mathrm{CP}+$ condition; [24]). CP was developed and tested with the goals of increasing birth weight, decreasing prematurity and improving patient and healthcare provider satisfaction [42], but not to address pregnant women's emotional needs. Thus, it is perhaps not surprising that significant findings were limited to the studies assessing infant outcomes. Nonetheless, the studies demonstrating benefits 
to maternal wellbeing with modified versions of the $\mathrm{CP}$ interventions suggest that $\mathrm{CP}$ could be further developed to also provide benefits for maternal perinatal wellbeing.

Although CP was not associated with maternal depressive symptoms, other empowerment interventions seemed to be associated with lower depressive symptoms postpartum. It appears that the successful interventions were those that aimed to provide women with the coping skills for the stressors ahead. For example, the successful COPE intervention was conceptualized to empower parents, through guided education, to cope with the needs of premature infants, reduce parenting anxiety, and increase child care efficacy. Other interventions successful at improving maternal depressive symptoms were the Mom Power program, aimed at emphasizing an internal health locus of control, and the intervention improving parent-to-parent and parent-toprovider dialogue. Similar to COPE, these interventions were developed to improve parental wellbeing. Providing some additional support for a link between women's empowerment in the perinatal period and improved maternal mental health comes from the six observational studies, all of which yielded at least some evidence of a link between empowerment and maternal mood. In contrast, $\mathrm{CP}$ and the Guided Participation Intervention focused on improving infant outcomes instead of maternal emotional needs, which may explain the null findings reported for maternal depressive symptoms.

While the CP intervention seems to be effective in improving infant birth outcomes in most studies, not all studies yielded significance. One possibility is that relevant confounding variables that were not statistically controlled for contributed to these null findings. For example, studies with null findings tended to have significantly more primiparous [41] and younger [37] women in the $\mathrm{CP}$ groups. They were also more likely to have rather homogenous samples, such as women in the military, with less ethnic diversity, or samples with a high proportion of disadvantaged or low-income women [37, 40]. Others include only parents of severely LBW infants $(\geq 1250 \mathrm{~g})$, have inconsistent intervention lengths, and report dose-response effects [22, 34], which may have also contributed to the null findings. Variations in social and material disadvantage [43], as well as in perceptions of disadvantage in education, employment, and economic status [44], may explain variations in efficacy of empowerment interventions.

It should be noted that this review did not aim to comprehensively review all possible maternal and infant health benefits that may be associated with women's empowerment. Instead, it focused on one specialized aspect of this association, specifically, perinatal depressive symptoms and PTB/LBW. This is not to say that empowerment does not affect women's and children's lives in many other important ways, but rather that these are some of the earliest health benefits that can be assessed. There is ample evidence that maternal perinatal depressive symptoms continue to have negative consequences for the health and wellbeing of the mother and child. For example, associations have been shown with infant negative affectivity [45], poor mother-infant bonding [46], elevated parenting stress [47], as well as physical and mental illness [48]. Similarly, PTB and LBW have enduring adverse consequences for child health and developmental outcomes such as increased risk for neurodevelopmental disabilities [49], attention difficulties [50], and cardiovascular disease later in life [51]. Given these associations, it appears likely that perinatal empowerment is associated with other health benefits to mother and infant, some of which may also be longer lasting. While important, these studies were considered to be beyond the scope of this review.

Empowerment was not directly measured in any of the intervention studies, with the exception of a single study measuring changes in internal health locus of control, a concept related to empowerment [12]. All interventions included at least an element of empowerment (Table 1), and it seems likely that supporting women's empowerment was a contributor to the health benefits observed. Nonetheless, it cannot be concluded with confidence that women's perceptions of empowerment changed in response to the intervention or, if they did, whether an increase in empowerment led to the observed health benefits. There is a need for studies that test whether empowerment is indeed a pathway through which these interventions contribute to improving maternal and infant health outcomes. We recommend that future studies, but in particular intervention studies, administer a direct measure of empowerment before and after the intervention.

\section{Recommendations for future work}

It is encouraging that the overall pattern observed in this small literature review is suggestive of significant associations between maternal empowerment-related concepts, perinatal depressive symptoms, and prematurity. To move this literature forward, both theoretically and in terms of the development of successful interventions, we propose several future directions that seem particularly promising, in our view.

First, while most studies provide evidence for an association between empowerment-related concepts and perinatal depressive symptoms or prematurity, we also identified some studies that report null findings. These inconsistencies could be the result of different definitions of empowerment and of differences in how empowerment was measured or supported through interventions. It is also possible that the divergent findings are the result of 
differences in sample composition, including, for example, age, ethnicity, and socioeconomic status. Moreover, a portion of the studies reviewed here included relatively small sample sizes and some were underpowered because they were originally designed to investigate outcomes other than $\mathrm{PTB} / \mathrm{LBW}$ and perinatal depressive symptoms $[22$, 29]. We recommend that future, adequately powered studies carefully test the role of possible moderators in the link between women's empowerment, perinatal depressive symptoms and prematurity, and that more detailed attention will be given to methods of measuring or supporting empowerment.

Moreover, we note that existing studies have focused on empowerment as it specifically relates to women's parental role. While the parental role is perhaps most salient in the context of empowerment of pregnant women and new mothers, other significant life changes occur with the birth of a child, in particular the birth of a first child. Across many cultures, new mothers often scale back on or halt their involvement in non-parental societal roles such as work outside the home, leading to decreases in financial independence as well as changes in social relationships and social status. We could not identify any studies that tested whether the empowerment of pregnant or postpartum women in domains other than the parental one is associated with perinatal depressive symptoms or prematurity. It would be an important contribution to the literature to study the relative impact of different facets of empowerment during the perinatal period on maternal and infant birth outcomes, because this knowledge would provide the groundwork for targeted interventions.

Related to the above, we further observe that studies sometimes use a vague conceptualization of empowerment that may be confounded with other interpersonal processes in group intervention studies. For example, the use of group prenatal care models gives rise to companionship and social support as confounding variables because these group processes are distinct from empowerment, but also may be associated with risk of perinatal depressive symptoms [52, 53]. Moreover, many interventions aimed to empower through provision of information, knowledge, and health literacy, but they did not include a measure of empowerment. Including a measure of empowerment in the intervention studies would allow for the identification of particular components of empowerment, such as increases in selfcompetence that may be particularly beneficial for reducing perinatal depressive symptoms and PTB or LBW. In observational studies, the operationalization of empowerment is somewhat clearer and includes increases in domestic decision-making power, financial autonomy, and internal locus of control.

Finally, we note that the literature on women's empowerment and $\mathrm{PTB} / \mathrm{LBW}$ is distinct from that on empowerment and perinatal depressive symptoms. This may be because interventions either focused on improving infant outcomes or on reducing postpartum depressive symptoms in mothers of infants that were already born premature. However, there is evidence that maternal perinatal depression and prematurity are correlated and may, in fact, share pathophysiological pathways [11, 54, 55]. The role of perinatal empowerment as a factor associated with physiological pathways related to both perinatal depressive symptoms and prematurity risk therefore merits further investigation.

\section{Conclusion}

In conclusion, the empirical evidence is promising and suggests that women's empowerment and interventions supporting empowerment are associated with reduced perinatal depressive symptoms and PTB or LBW under certain conditions. However, more research is necessary before concrete recommendations can be made. In particular, it is important to improve our understanding of aspects of empowerment that are (1) protective for specific maternal and infant health outcomes, and (2) beneficial across a variety of populations versus specific subgroups of women. Studies testing the effectiveness of specific facets of empowerment on health outcomes and studies further investigating the role of confounding variables, including but not limited to ethnicity and socioeconomic status, would be useful first steps to achieve this goal. A better understanding of the subtleties of the link between empowerment and health will contribute to enhancing the content specificity and efficacy of empowerment interventions. Studies should also be adequately sized to provide sufficient statistical power to accommodate more complex statistical analyses, such as those testing mediational models of how empowerment is substantiated biologically. Doing so would provide the opportunity to uncover biobehavioral mechanisms that may lead to improvement in perinatal depressive symptoms as well as PTB and LBW rates. Given the potential for empowerment in the perinatal period to provide benefits for both maternal and infant health, this topic merits further investigation.

\section{Additional file}

Additional file 1: Open peer review. (PDF $271 \mathrm{~kb}$ )

\section{Abbreviations}

LBW: low birthweight; PTB: preterm birth; CP: CenteringPregnancy;

COPE: Creating Opportunities for Parent Empowerment; PRISMA: Preferred Reporting Items for Systematic Reviews and Meta-Analyses

\section{Funding}

This article is part of a special issue on women's health and empowerment, led and sponsored by the University of California Global Health Institute,

Center of Expertise on Women's Health, Gender, and Empowerment. It also received feedback at a workshop partially funded by the NIH NCATS UCLA CTSI Grant Number UL1TR000124. 


\section{Open peer review}

Peer review reports for this article are available in Additional file 1.

\section{Availability of data and materials}

The data supporting our results can be obtained on request to the corresponding author.

\section{About this supplement}

This article has been published as part of BMC Pregnancy and Childbirth Volume 17 Supplement 2, 2017: Special issue on women's health, gender and empowerment. The full contents of the supplement are available online at https://bmcpregnancychildbirth.biomedcentral.com/articles/supplements/ volume-17-supplement-2.

\section{Authors' contributions}

Both authors contributed critically to the manuscript and approved the final version.

\section{Ethics approval and consent to participate}

Not applicable.

\section{Consent for publication}

Not applicable.

\section{Competing interests}

The authors declare that they have no competing interests.

\section{Publisher's Note}

Springer Nature remains neutral with regard to jurisdictional claims in published maps and institutional affiliations.

\section{Published: 8 November 2017}

\section{References}

1. Alemayehu YK, Theall K, Lemma W, Hajito KW, Tushune K. The role of empowerment in the association between a woman's educational status and infant mortality in Ethiopia: Secondary analysis of demographic and health surveys. Ethiopian J Health Sci. 2015;25(4):353-62.

2. Waiswa P, O'Connell T, Bagenda D, Mullachery P, Mpanga F, Henriksson DK, Katahoire AR, Ssegujja E, Mbonye AK, Peterson SS. Community and District Empowerment for Scale-up (CODES): A complex district-level management intervention to improve child survival in Uganda: study protocol for a randomized controlled trial. Trials. 2016:17:135.

3. Will JC, Khavjou O, Finkelstein EA, Loo RK, Gregory-Mercado K. One-year changes in glucose and heart disease risk factors among participants in the WISEWOMAN programme. Eur Diabetes Nurs. 2007;4(2):57-63.

4. Upadhyay UD, Gipson JD, Withers M, Lewis S, Ciaraldi EJ, Fraser A, Huchko MJ, Prata N. Women's empowerment and fertility: A review of the literature. Soc Sci Med. 2014;115:111-20. http://doi.org/10.1016/j.socscimed.2014.06.014.

5. Shain RN, Piper JM, Newton ER, Perdue ST, Ramonths R, Champion JD, Guerra FA. A randomized controlled trial of a behavioral intervention to prevent sexually transmitted disease among minority women. N Engl J Med. 1999;340:93-100.

6. Barber SL, Gertler PJ. Empowering women to obtain high quality care: evidence from an evaluation of Mexico's conditional cash transfer programme. Health Policy Plan. 2009;24(1):18-25.

7. Weinstock M. The potential influence of maternal stress hormones on development and mental health of the offspring. Brain Behav Immun. 2005; 19(4):296-308. doi:10.1016/j.bbi.2004.09.006.

8. Yim IS, Glynn LM, Schetter CD, Hobel CJ, Chicz-Demet A, Sandman CA. Risk of postpartum depressive symptoms with elevated corticotropin-releasing hormone in human pregnancy. Arch Gen Psychiatry. 2009;66(2):162. doi:10. 1001/archgenpsychiatry.2008.533.

9. Roberts E, Wood P. Birth weight and adult health in historical perspective: Evidence from a New Zealand cohort, 1907-1922. Soc Sci Med. 2014;107: 154-61. doi:10.1016/j.socscimed.2014.02.015.

10. Yim IS, Stapleton LR, Guardino CM, Hahn-Holbrook J, Schetter CD. Biological and psychosocial predictors of postpartum depression: Systematic review and call for integration. Annu Rev Clin Psychol. 2015;11(1):99-137. doi:10. 1146/annurev-clinpsy-101414-020426.
11. Halbreich $U$. The association between pregnancy processes, preterm delivery, low birth weight, and postpartum depressions: The need for interdisciplinary integration. Am J Obstet Gynecol. 2005;193(4):1312-22.

12. Monthshki M, Beydokhti TB, Cheravi K. The effect of educational intervention on prevention of postpartum depression: an application of health locus of control. J Clin Nurs. 2013;23(15-16):2256-63.

13. Moher D, Liberati A, Tetzlaff J, Altman DG. Preferred reporting items for systematic reviews and meta-analyses: The PRISMA statement. J Clin Epidemiol. 2009:62:1006-12.

14. O'Mahony JM, Donnelly $\Pi$. How does gender influence immigrant and refugee women's postpartum depression help-seeking experiences? J Psychiatr Ment Health Nurs. 2013;20(8):714-25.

15. Tanner-Smith EE, Steinka-Fry KT, Lipsey MW. The effects of CenteringPregnancy group prenatal care on gestational age, birth weight, and fetal demise. Matern Child Health J. 2014;18(4):801-9.

16. Richardson A, Field T, Newton R, Bendell D. Locus of control and prenatal depression. Infant Behav Dev. 2012;35(4):662-8.

17. Grady MA, Bloom KC. Pregnancy outcomes of adolescents enrolled in a CenteringPregnancy program. J Midwifery Womens Health. 2004;49(5):412-20.

18. Liu C, Chao Y, Huang C, Wei F, Chien L. Effectiveness of applying empowerment strategies when establishing a support group for parents of preterm infants. J Clin Nurs. 2010;19(11-12):1729-37.

19. Study Quality Assessment Tools - NHLBI, NIH. 2014. https://www.nhlbi.nih gov/health-pro/guidelines/in-develop/cardiovascular-risk-reduction/tools. Accessed 02 Oct 2016

20. Gibson C, Callands TA, Magriples U, Divney A, Kershaw T. Intimate partner violence, power, and equity among adolescent parents: Relation to child outcomes and parenting. Matern Child Health J. 2015;19(1):188-95. http:// dx.doi.org/10.1007/s10995-014-1509-9.

21. Rising S. CenteringPregnancy: An interdisciplinary model of empowerment. J Nurse Midwifery. 1998;43(1):46-54. doi:10.1016/s0091-2182(97)00117-1.

22. Pridham K, Brown R, Clark R, Limbo RK, Schroeder M, Henriques J, Bohne E. Effect of guided participation on feeding competencies of mothers and their premature infants. Res Nurs Health. 2005:28(3):252-67.

23. Muzik M, Rosenblum KL, Alfafara EA, Schuster MM, Miller NM, Waddell RM, Kohler ES. Mom power: Preliminary outcomes of a group intervention to improve mental health and parenting among high-risk mothers. Arch Womens Ment Health. 2015:18(3):507-21.

24. Ickovics JR, Reed E, Magriples U, Westdahl C, Rising SS, Kershaw TS. Effects of group prenatal care on psychosocial risk in pregnancy: Results from a randomized controlled trial. Psychol Health. 2011;26(2):235-50.

25. Kennedy HP, Farrell T, Paden R, Hill S, Jolivet RR, Cooper BA, Rising SS. A randomized clinical trial of group prenatal care in two military settings. Mil Med. 2011;176(10):1169-77.

26. Melnyk BM, Alpert-Gillis L, Feinstein NF, Fairbanks E, Schultz-Czarniak J, Hust D, Sinkin MR. Improving cognitive development of low-birth-weight premature infants with the COPE program: A pilot study of the benefit of early NICU intervention with mothers. Res Nurs Health. 2001;24(5):373-89.

27. Melnyk BM, Feinstein NF, Alpert-Gillis L, Fairbanks E, Crean HF, Sinkin RA Gross SJ. Reducing premature infants' length of stay and improving parents' mental health outcomes with the Creating Opportunities for Parent Empowerment (COPE) neonatal intensive care unit program: A randomized, controlled trial. Pediatrics. 2006:118(5):1414-27.

28. Melnyk BM, Crean HF, Feinstein NF, Fairbanks E. Maternal anxiety and depression after a premature infant's discharge from the neonatal intensive care unit. Nurs Res. 2008;57(6):383-94.

29. Robertson B, Aycock DM, Darnell LA. Comparison of CenteringPregnancy to traditional care in Hispanic mothers. Matern Child Health J. 2009;13(4):407-14.

30. Ali NS, Ali BS, Azam IS. Postpartum anxiety and depression in peri-urban communities of Karachi, Pakistan: A quasi-experimental study. BMC Public Health. 2009;9:384. doi:10.1186/1471-2458-9-384.

31. Rahman A, Sikander S, Malik A, Ahmed I, Tomenson B, Creed F. Effective treatment of perinatal depression for women in debt and lacking financial empowerment in a low-income country. Br J Psychiatry. 2012;201(6):451-7.

32. Chien L, Tai C, Yeh M. Domestic decision-making power, social support, and postpartum depression symptoms among immigrant and native women in Taiwan. Nurs Res. 2012;61(2):103-10. http://dx.doi.org/10.1097/NNR. ob013e31824482b6

33. Ickovics J, Kershaw TS, Westdahl C, Rising SS, Klima C, Reynolds H, Magriples U. Group prenatal care and preterm birth weight: Results from a matched cohort study at public clinics. Obstet Gynecol. 2003;102(5):1051-7. 
34. Ickovics JR, Kershaw TS, Westdahl C, Magriples U, Massey Z, Reynolds H, Rising SS. Group prenatal care and perinatal outcomes. Obstet Gynecol. 2007;110(2):330-9.

35. Ickovics JR, Earnshaw V, Lewis JB, Kershaw TS, Magriples U, Stasko E, Tobin $\mathrm{JN}$. Cluster randomized controlled trial of group prenatal care: perinatal outcomes among adolescents in New York city health centers. Am J Public Health. 2016;106(2):359-65. doi:10.2105/ajph.2015.302960.

36. Barr WB, Aslam S, Levin M. Evaluation of a group prenatal care-based curriculum in a family medicine residency. Fam Med. 2011;43(10):712-7.

37. Klima C, Norr K, Vonderheid S, Handler A. Introduction of CenteringPregnancy in a public health clinic. J Midwifery Womens Health. 2009;54(1):27-34.

38. Picklesimer AH, Billings $\mathrm{D}$, Hale N, Blackhurst $\mathrm{D}$, Covington-Kolb $\mathrm{S}$. The effect of CenteringPregnancy group prenatal care on preterm birth in a lowincome population. Am J Obstet Gynecol. 2012:206(5):415e1-7.

39. Tandon SD, Colon L, Vega P, Murphy J, Alonso A. Birth outcomes associated with receipt of group prenatal care among low-income Hispanic women. J Midwifery Womens Health. 2012;57(5):476-81.

40. Trudnak TE, Arboleda E, Kirby RS, Perrin K. Outcomes of Latina women in Centering Pregnancy group prenatal care compared with individual prenatal care. J Midwifery Womens Health. 2013;58(4):396-403.

41. Walton RB, Shaffer S, Heaton J. Group prenatal care outcomes in a military population: A retrospective cohort study. Mil Med. 2015;180(7):825-9.

42. Dellos L, Marshall KK. Reducing preterm birth in lowa with CenteringPregnancy. Proc Obstet Gynecol. 2011;2(2):1-5.

43. Abrams LS, Curran L. "And you're telling me not to stress?" A grounded theory study of postpartum depression symptoms among low-income mothers. Psychol Women Q. 2009;33(3):351-62.

44. Dolbier CL, Rush TE, Sahadeo LS, Shaffer ML, Thorp J. Relationships of race and socioeconomic status to postpartum depressive symptoms in rural African American and non-Hispanic White women. Matern Child Health J. 2013;17(7):1277-87.

45. Rouse MH, Goodman SH. Perinatal depression influences on infant negative affectivity: Timing, severity, and co-morbid anxiety. Infant Behav Dev. 2014; 37(4):739-51. doi:10.1016/j.infbeh.2014.09.001.

46. Reay R, Matthey S, Ellwood D, Scott M. Long-term outcomes of participants in a perinatal depression early detection program. J Affect Disord. 2011; 129(1-3):94-103. doi:10.1016/j.jad.2010.07.035.

47. Guo N, Bindt C, Te Bonle M, Appiah-Poku J, Tomori C, Hinz R, Barthel D, Schoppen S, Feldt T, Barkmann C, Koffi M, Loag W, Nguah SB, Eberhardt KA, Tagbor H, Bass JK, N'Goran E, Ehrhardt S. Mental health related determinants of parenting stress among urban mothers of young children: Results from a birth-cohort study in Ghana and Côte d'Ivoire. BMC Psychiatry. 2014;14:156

48. Josefsson A, Sydsjö G. A follow-up study of postpartum depressed women: recurrent maternal depressive symptoms and child behavior after four years. Arch Womens Ment Health. 2007;10(4):141-5.

49. Wilson-Costello D, Friedman H, Minich N, Fanaroff AA, Hack M. Improved survival rates with increased neurodevelopmental disability for extremely low birth weight infants in the 1990s. Pediatrics. 2005;115(4):997-1003.

50. Wilson-Ching M, Molloy CS, Anderson VA, Burnett A, Roberts G, Cheong JL, Doyle LW, Anderson PJ. Attention difficulties in a contemporary geographic cohort of adolescents born extremely preterm/extremely low birth weight. Int Neuropsychol. 2003;19(10):1097-108.

51. Bayman E, Drake AJ, Piyasena C. Prematurity and programming of cardiovascular disease risk: A future challenge for public health. Arch Dis Child Fetal Neonatal Ed. 2014:99(6):510-4.

52. Lancaster CA, Gold KJ, Flynn HA, Yoo H, Marcus SM, Davis MM. Risk factors for depressive symptoms during pregnancy: A systematic review. Am J Obstet Gynecol. 2010;202(1):5-14

53. Robertson $E$, Grace $S$, Wallington $T$, Stewart DE. Antenatal risk factors for postpartum depression: A synthesis of recent literature. Gen Hosp Psychiatry. 2004;26(4):289-95. doi:10.1016/j.genhosppsych.2004.02.006.

54. Smith MV, Shao L, Howell H, Lin H, Yonkers KA. Perinatal depression and birth outcomes in a healthy start project. Matern Child Health J. 2011;15(3):401-9.

55. Field T. Prenatal depression effects on early development: A review. Infant Behav Dev. 2011;34(1):1-14. doi:10.1016/j.infbeh.2010.09.008.

\section{Submit your next manuscript to BioMed Central and we will help you at every step:}

- We accept pre-submission inquiries

- Our selector tool helps you to find the most relevant journal

- We provide round the clock customer support

- Convenient online submission

- Thorough peer review

- Inclusion in PubMed and all major indexing services

- Maximum visibility for your research

Submit your manuscript at www.biomedcentral.com/submit
Biomed Central 